\title{
The Brand Strategy Analysis: Surviving and Competing in The Disruptive Era
}

\author{
Irsad Andriyanto ${ }^{1}$, Karebet Gunawan ${ }^{2}$ and Suhadi ${ }^{3}$ \\ \{irsad.smg@gmail.com $\left.{ }^{1}\right\}$ \\ ${ }^{1,2,3}$ Department of Sharia and Islamic Economy, IAIN Kudus, Ngembalrejo, Kudus, Indonesia
}

\begin{abstract}
The umrah travel industry is continuously growing while negative news of the industry still exists. Travel organizers should act professional service while complying with government rules. Consequently, many brands came offering interesting promises to serve pilgrims. This research aimed to reveal the brand awareness brand management model and its development among umrah travel organizers. Key informant interviews with associated secondary data mining were important sources of data gathering. Furthermore SWOT analysis used in data processing to uncover related information for strengths weaknesses opportunities threats and rivalry position among organizers. The results suggested five ways to build brand awareness: social media optimization partnering with public figures whose great influence posters forming a community of umrah alumni and applying a famous brand name. Travel organizers could take advantage of using a prominent brand and cede their entire policies of the parent organization. They might empower the parent brand operational experience to support marketing activities. Moreover, the organizers supervised their own brand mastering overall decision making. Those are three actions in the framework of brand management. Equally for the evolution of a brand strategy among travel organizers each can choose whether aggressive cautious defensive or competitive strategy.
\end{abstract}

Keywords: Brand, Strategy, Awareness, SWOT, Aggressive.

\section{Introduction}

For the past four years of the umrah departure from Indonesia are experiencing a real substantial growth. The brands of umrah organizers are springing up in the mass media offer sacred promises to the candidate performing umrah towards the Baitullah-Mecca with numerous facilities. This is quite reasonable because the waiting period for the Hajj is getting longer. Moreover, the organizers occupy various strategies, capturing the requests to take advantage. Conversely, umrah departure frauds meet the preaching of the mass media at the beginning of 2017. Problems started in March 2017 when First Travel, a famous umrah organizer failed to deliver its. In June 2017, 600 clients from East Java were also stranded for many days didn't know when they would go. First Travel could not afford any explanations while complaints were rising as many of these clients have been delayed. This case impacted on the icon of the umrah organizer industry in Indonesia being violated. Consequently, the requests of umrah departure increase accompanied by raising frauds formed a dilemmatic condition.

Victims of First Travel's fraud reached 58,682 pilgrims, while Abu Tour reached 86,000, and Hannien Tour reached 4,126 pilgrims. All were victims of brands providing the promise to perform umrah at low prices with great facilities through both electronic and printed media. Accordingly, this condition forced the government (Religious Affairs Ministry), the police, 
House of Representative, and Financial Service Authority to pay attention and form a Task Force Team in dealing with the problem which soon investigated First Travel.

The public attention of the negative issues in umrah organizing forces companies (umrah organizers) to create a strategy preserving public trust. The effectiveness of umrah organizer brand strategy becomes urgent. Consequently, the umrah travel organizer whose no negative image has large opportunities for serving an umrah travel services market still open expansive so they are straining to build brand awareness.

\section{Theoretical Framework}

\subsection{Brand Positioning}

A brand gains its position when known by consumers and parties associated with the brand in the marketplace. Accordingly, a good brand positioning strategy should have characteristics such as relevant, clear, unique, desirable, deliverable, points of difference, recognizable feature, and validated by the customer.

Kotler \& Keller said that brand positioning is an act of designing the company's offering and image to occupy a distinct place in the mind of the target market (Kotler and Keller, 2016). Furthermore, the positioning shows how a brand is better and different from its competitors based on the functional aspect of a product or service offered (Gelder, 2004). Consequently, the aim of brand positioning is to achieve a brand image by several levels of positioning including positioning by price, quality, quantity, sizes, corporate name, color and graphics, events, personality/celebrity, and visibility (Edema, 2014).

\subsection{Brand Identity}

The word brand can have the same meaning as a name, logo, and symbols that differentiate a product or service from others, notwithstanding the brand has wider coverage for its varieties that leads to an identity (Jackson et al., 2014). Subsequently, a powerful identity contributes consumer loyalty creation. Effective identity drives company benefit through three ways; sets up the character and value of a product, delivers the character in a unique way, and provides product emotional strength. Furthermore, companies express their product identity using any way of communication and each contract against brand (touch point). It should likewise be expressed by symbols, written media, audio visuals, mood, and employee behaviour (Kotler and Keller, 2016).

A qualified brand is a brand in contrast with how its appearance, nuances, and behaviours make it different from others (Budelmann et al., 2010). The word "qualified" means that brands should be capable to distinguish themselves in contrast with their main competitors and the overall market at all. The contrast brand identity represents the starting point of positioning that should focus on differentiation. Accordingly, a company may use the graphical style and meaning display (visual identity) to set up the identity. This visual identity triggers a consumer perception, furthermore, it creates a brand association (Huang and Sarigöllü, 2012).

\subsection{Brand Personality}

The brand personality refers to the personality traits associated with a brand, whereas consumer can relate it to the brand. The effectiveness of the brand increases its equity that consumers enjoy a consistent set of traits. This personality is a qualitative measurement that a brand gains to its functional benefits. Once brand personality developed to enhance the brand 
attractiveness, furthermore brand personality take the form of actual people or an animated figure (Gelder, 2006). Dove, in an example, chooses sincerity as its brand personality, allowing the feminine consumers being attracted. Luxury brands, such as Michael Kors and Chanel, rely on the sophistication where their brand personality focuses on an high-class, trendy and glamorous lifestyle, which attracts a high-spending consumer base. Subsequently, REI, the outdoor clothing, footware and gear retail store, has a unique brand personality; they focus on serving their audience (who are typically outdoorsy, adventurous people) to be strong and resilient.

Customers are more likely to buy a brand if their own character is similar to its personality, whereas there are five main types of brand personalities: sincerity, ruggedness, competence, sophistication, and excitement. First, excitement is synonymous with a carefree, spirited and youthful attitude. Second, sincerity is a symbol of kindness, thoughtfulness, and an orientation toward family values. Third, ruggedness is thought of as rough, tough, outdoorsy and athletic. Fourth, competence, in the mind of a consumer, is similar to be successful, accomplished and influential, highlighted by leadership. Fifth, sophistication makes a brand seem elegant, prestigious and sometimes even pretentious (Gelder, 2004).

\subsection{Brand Communication}

Without on-going brand communication, the worth of a brand's identity would become obsolete, even though the identity of the brand is regarded as the most fundamental asset to its equity. The view of branding has been highlighting the communication as part of a brand management integral process. Accordingly, a company management necessarily involves communication into all its functions (production, finance, human resource, marketing, etc.). Effective brand communication establishes a brand's reputation with consumers, ordinarily brand communication occurs every time consumers interact with, such as when they see the logo, view company product, view brand content, or meet the brand in person.

Brands must develop reliable ways to reach their customers, and get the message considered. Consequently, brands achieve maximum impact when all channels are highly integrated. Meanwhile, the communication channels are classified as offline and online media in today's marketplace. A company can communicate their brand through a variety of ways such as advertising, sales promotion, event or public relations (Schultz et al., 2013).

\subsection{Brand Awareness}

The brand awareness is particularly important when launching new products and services, which allows a company to differentiate itself from competitor-offered products and services. According to Aaker, it means the ability of consumers to recognize and remember a brand in a variety of situations. The content of brand awareness consists of brand recall and brand recognition, whereas brand recall means that when consumers see the category of product or service, they can remember the brand appropriately (AAker and McLoughlin, 2010). While brand recognition means that consumer capable to identify when there are signs of a brand. Consequently, brand awareness is the degree of consumer awareness of a brand and its related products that measure brand accessibility in customers' memory (Ehsan Malik et al., 2013).

The awareness of a brand shows how consumers understand the possibility of products or services available and accessible in the market. Thus, the brand offers the quick look of a customer to understand the differentiation of product or service offered in a particular category . Company such Coca-Cola uses their brand to present their products and increase sales. The 
Company has employed strategies to increase awareness of its consumers to the brand, which has directly transformed into higher sales over the years. If the awareness of the brand is being high, it typically serves an economic chance that invites competitors from achieving additional market share (Chi et al., 2009; Ehsan Malik et al., 2013; Huang and Sarigöllü, 2012; Karam and Saydam, 2015).

\subsection{Brand Management Models}

The process of brand management starts by setting brand principles, disseminate and take copious notes, then deploy them into organizations to determine the management structure (parties or persons authorized). These steps are called "brand-driven marketing management". Nevertheless, the problem is how to unite ideas of a brand with issues outside the company and business activities, while directing its compatibility with brand principles.

According to Kotler, the problem of brand strategy development based on three types of business and brand strategy. The three types are the package type, the component type, and customer interface type (Kotler and Keller, 2016). The package type state that company sells products that quickly runs out called "fast moving consumer good". The consumer of this type always compares product features with others before buying. Subsequently, the brand becomes an important feature for consumers' decision making. They will associate product name to a specific category in order to maintain the position on the top of mind brand awareness category. Component type states that a company sells product or service in serving industry needs. The product is not intended for the end-user consumer, ordinarily, component type looks like business-to-business model. In consequence, the role of brands in this model is less important. The customer interfaces type whereas a company produces a product or service must be at the join with the service. In this model, marketing plays an important role in motivating and coaching the team organization in serving customers well.

Table 1. The type of brand strategic model.

\begin{tabular}{cc}
\hline Brand Type & Strategic Model \\
\hline Package type & $\begin{array}{c}\text { Emphasize emotional values and differentiation } \\
\text { The role of advertising is very dominant (main strategy) } \\
\text { The main target }=\text { end-user consumer }\end{array}$ \\
\hline $\begin{array}{c}\text { Component type } \\
\text { Customer Interface } \\
\text { Type }\end{array}$ & Inderstand the interests of Stakeholders (main strategy) \\
& The main target = agent \\
\hline & The main target = agents and employees \\
\hline
\end{tabular}

This is a qualitative study which nature is descriptive and explanatory means that the researcher gave a description of a complex situation and the direction for subsequent researchers. The researcher becomes a fundamental tool in qualitative inquiry, especially for data gathering. The Research Data obtained through observation and interview against umrah company managers' in Kudus.

The steps of data analysis in this study refer to Miles and Huberman qualitative data analysis model (Miles et al., 2014). Furthermore, using SWOT analysis is powerful to evaluate the strengths, weaknesses, opportunities, and traits of umrah travel organizers' in Kudus. The SWOT analysis is the systematic identification of various factors to formulate a company or organization strategy. The analysis is based on the relationship or interaction between internal 
elements; i.e., Strength and Weakness, against external elements; Opportunities and Threats. Many companies use the analysis as a technical business analysis for each product and service when deciding the best way for growth achievement in the future (Kuratko et al., 2014).

Strengths include management expertise, positive cash flow, and well-known brand, while weakness includes the lack of spare production capacity and the absence of a reliable supplier. On the other hand, an opportunity seems to be a niche market that less of company attention, whereas threats, includes competitors entering a niche profitable market. The variables vary for each organization depending on its analysis.

The SWOT matrix was a combination of four factors used to analyze business or organization for better decision making. The SWOT Matrix was used to draw up a strategy that clearly described opportunities and threats, which could be adapted to strengths and weaknesses. This resulted in a matrix of four possibilities strategy; S-O strategies (StrengthOpportunity), W-O strategies (Weakness-Opportunity), S-T Strategies (Strength-Threat) and the W-T Strategies (Weakness-Threat) (Helms and Nixon, 2010).

\section{Result And Discussion}

The umrah grows into a lucrative business with seemingly endless demand, particularly in Indonesia, a country with the world's largest Muslim population. The better purchasing power seems to be a factor raising interests of umrah, besides growing consciousness to enhance the worship as well as a long waiting period of hajj. Subsequently, these conditions provide a great business opportunity for umrah travel organisers in Indonesia.

Table 2. The list of umrah travel organizers in kudus.

\begin{tabular}{cc}
\hline Name & Office Position \\
\hline Arwaniyyah Tour and Travel & Head office \\
\hline Prima Happy Wisata & Branch office \\
\hline Fath Indah Travel & Branch office \\
\hline Basya Fajria Setia & Marketing office \\
\hline Arminareka Perdana & Marketing office \\
\hline Impressa Media Wisata & Marketing office \\
\hline Zhafira Mitra Madina & Marketing office \\
\hline
\end{tabular}

Table 2 showed that Arwaniyyah is the only licensed umrah travel organisers in Kudus. Therefore, it can be noted that umrah travel agencies' in Kudus, besides Arwaniyyah, PT. Happy Prima Wisata and PT Fath Indah Travel are the agencies of umrah travel organiser who don't have yet license in Kudus.

\subsection{Brand Awareness Strategy Building}

Many companies create an official account and other social media groups as an effort to build interactive communication serve better through applications such as Facebook, WhatsApp, Instagram, and Twitter. Umrah travel organizers in Kudus generally have been using social media as a way of introducing their brand. Whatsapp was considered the most common media used to communicate. Each umrah travel organisers has a WhatsApp group consists of the prospective pilgrims and umrah pilgrims alumni as its members. Furthermore, Facebook is the second application often used in terms of uploading guidance activities and umrah pilgrims' activities. 
One of brand strategy elements is a brand communication as a relationship between a company and its customers in emotional connection (Morrison et al., 2003). Even Arminareka mentions such activities as "ta'awun" culture which held intensively in every week and month. Subsequently, optimum service quality will create word of mouth, especially coming from community leaders and alumni that is one of all activity goals. Word of mouth has been considered as an effective marketing tool, introducing brand at low-cost. Accordingly, perceived service quality and pilgrim's experience was recognized as a capital to umrah travel organisers communicates with the prospective pilgrims (Kaye, 2014).

The conclusion is umrah travel organizers' in Kudus used five ways as their strategy creating brand awareness. First, optimizing social media. Second, partnering with community leaders who have great influence (public figures). Third, conveyed the message a brand umrah travel organisers through brochures and banners. Fourth, creating a word of mouth by maximizing service quality and forming alumni association, and the fifth, using the strong brand name and symbol of a famous brand that has been known to the public.

\subsection{Brand Management Model Analysis}

The entire umrah travel organizers in Kudus seemed to be implementing the principles except for PT. Basya Fajria Setia. Arwaniyyah Tour \& Travel use the fame of Arwaniyyah for its brand name. Even the logo same as the Foundation Arwaniyyah logo. Arwaniyyah Tour $\&$ Travel is one of the business units under Arwaniyyah Foundation. The parent manages entire activities include existing policies and regulations. Arwaniyyah Tour \& Travel conducted its operational and tactical strategic domain only, while the authority controlled by its parent organizations as Arwaniyyah Foundation.

HPW Kudus Tour \& Travel use the fame of HPW who has already experienced running operational umrah travel. The leadership of HPW Kudus tour \& travel run dual role of the brand management model. First, as a director and a manager that should pay attention to manage the brand. Second, play a role as an entrepreneur, whereas leadership becomes the personification of the brand and plays an important role in communicating the brand to a business environment.

Fath Indah Travel had the same model with HPW Tour \& Travel, notwithstanding the role of parent management policy more dominant than the role of Mr. Taat Subekti as leader of Kudus branch. Fath Indah brand management started from service and human resources standardization. Fath Indah Tour \& Travel is the only umrah travel organisers in Kudus that quick and responsive to government policy change, moreover, only Fath Indah Tour \& Travel brave to ensure verification through SiPatuh application.

PT. Arminareka Perdana is a umrah travel organisers get frequently media spotlight causing it's known to have a negative brand image. This is due to the person's behavior running the system of Multi Level Marketing (MLM). Moreover, it certainly had an impact on the equity value of Arminareka brand. Arminareka Perdana and Zhafirah Tour \& Travel adopted partnership model into their brand management brand. Both of them play a role as a partner, which met parent requirements to have a business license in organizing umrah travel services. In advance, Arminareka has an extensive network with a large number of agents, spreads in various parts of the County. Meanwhile, Zhafirah Tour \& Travel is more active doing its marketing activities through online and below the line advertising. Its marketing team active introducing the brand and update its business activities in social media. Noted that Zhafirah Tour \& Travel only has an active account and well systemized in delivering information. 
MAIS Tours \& travel Kudus does not have the full support from its parent in brand management, even its business license. However, MAIS business policy must be in alignment with government rules and policies. In comparison to others umrah travel organisers, MAIS brand awareness activities rated very weak, therefore it requires a lot of improvements facing the competition. One thing that makes MAIS still survive is its coordinator highly spirit and financial support to develop the brand in the County (AAker and McLoughlin, 2010).

The next umrah travel organiser is PT. Basya Fajria Setia that have full control in managing the brand, notwithstanding the umrah travel organisers didn't do its marketing activities massively because of the legality problem. Nevertheless, the model of brand management applied in accordance with Krake brand management model. Krake (2005) confirms the validity of the three guidance in brand management; concern on one or two strong brands, focused on the marketing program developed creatively, and use brand elements that well-integrated (Krake, 2005).

Based on the explanation, it can be concluded that umrah travel organisers in Kudus uses three brand management models. First, the join with the famous umrah travel organiser that has a strong influence as well as subject to the entire parent organization policy. Second, utilizing the operational experience and capability of parent umrah travel organisers to support its marketing activities. And third, managing his own brand to get full control over all decision making in brand management (Alif Fianto et al., 2014; Helms and Nixon, 2010; Rao Gundala and Khawaja, 2014).

\subsection{Brand Development Model Analysis}

Arwaniyyah Tour \& Travel has been famous for its service excellence that influent on the rising number of pilgrims. Accordingly, it's assumed that the organizer possesses the highest value of SWOT factors and deserves to be a benchmark in umrah travel industry. Table 4 showed the accumulation of internal and external factors among the six umrah travel organizers in Kudus.

Table 3. The SWOT indicators of umrah travel organizers.

\begin{tabular}{|c|c|}
\hline Strengths $(\mathrm{S})$ & $\begin{array}{l}\text { Brand awareness, operational experience, handling ability, physical office, } \\
\text { branch, and network }\end{array}$ \\
\hline $\begin{array}{l}\text { Weaknesses } \\
\text { (W) }\end{array}$ & Financial support, licence, salesforce \\
\hline $\begin{array}{c}\text { Opportunities } \\
(\mathrm{O})\end{array}$ & Positive market trends, trusts, long hajj waiting list, service diversification \\
\hline Threats $(\mathrm{T})$ & $\begin{array}{l}\text { Accreditation, industrial brand image, competitive market, trust } \\
\text { maintenance }\end{array}$ \\
\hline
\end{tabular}

Table 4. The SWOT matrix total score.

\begin{tabular}{cc}
\hline Name & Total score \\
\hline Fath Indah Travel & 5.5716 \\
\hline Zhafira Mitra Madina & 4.6759 \\
\hline Happy Prima Wisata & 4.5398 \\
\hline Arminareka Perdana & 3.6479 \\
\hline Basya Fajria Setia & 3.2668 \\
\hline Impressa Media Wisata & 2.5432 \\
\hline
\end{tabular}




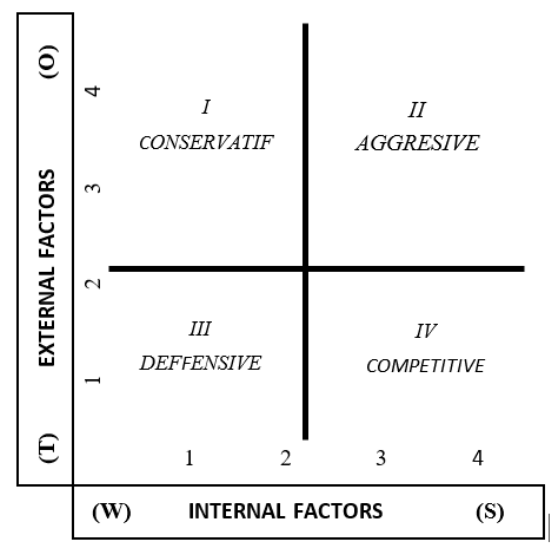

\section{Conclusions}

Fig.1. Matrix strategy based on SWOT analysis.

The business of umrah travel has been raising, nevertheless, the negative issues were still popping up. At least, there were five ways for umrah travel organizer in Kudus as their corporate strategy to build brand awareness. First, optimizing social media both online or offline. Second, partnering with community leaders who have great influence. Third, utilizing brochures and banners in term of offline marketing activities. Fourth, creating a word of mouth activity by way of maximizing service and form a community of alumni too. And fifth, using the brand name and symbol of a large brand that has been known to the public.

The umrah travel organisers in Kudus used three models of brand management. First, the umrah travel organisers utilized a famous brand that has a strong influence in a community. Besides, the company should obey the entire policy of its parent organization. Second, utilizing the parent's experience and the ability of its operational activities to support its marketing program. Third, the umrah travel organisers managed its own brand to get full control over all decision making in brand management.

Strategic priorities of developing umrah travel organizers suggested highlighting the strategy generated from its position in the SWOT matrix. The strategies were conservative, aggressive, defensive, and competitive. The SO strategy was based on the company way based on utilizing the entire resource. Zhafira Tour \& Travel and HPW Tour \& Travel were advised to implement WO strategy that based on exploring opportunities after minimizing the weaknesses that exist. In this case, it needed to design a turnaround strategy i.e. strategy revamp bow. Large external opportunities were important to attain, however, the internal problems or weaknesses in the internal brand were preferable to look for solutions. Arminareka Kudus, PT. Basya Fajria Setia and MAIS Kudus Tour \& Travel were recommended to perform WT strategy based on activities that were defensive, should minimize the weaknesses and avoid threats. Because of this condition, the brand was in danger and needed for solutions.

\section{References}

[1] AAker, D.A., McLoughlin, D., 2010. Strategic Market Management: Global Perspectives, 9th ed. New Jersey.

[2] Alif Fianto, A.Y., Hadiwidjojo, D., Aisjah, S., Solimun, S., 2014. The Influence of 
Brand Image on Purchase Behaviour Through Brand Trust. Bus. Manag. Strateg. 5, 58.

[3] Budelmann, K., Kim, Y., Wozniak, C., 2010. Brand Identity Essentials: 100 Principles for Designing Logos and Building Brands, 1st ed. Rockport Publishers, Beverly Massachusetts.

[4] Chi, H.K., Yeh, H.R., Yang, Y.T., 2009. The impact of brand awareness on consumer purchase intention: The mediating effect of perceived quality and brand loyalty. J. Int. Manag. Stud. 4, 135-144.

[5] Edema, A.J.M., 2014. Branding and Brand Positioning: A Conceptual Conflict Perspective in Product and Corporate Strategies. Sci. Res. J. 2, 49-54.

[6] Ehsan Malik, M., Mudasar Ghafoor, M., Kashif Iqbal, H., Riaz, U., ul Hassan, N., Mustafa, M., Shahbaz, S., 2013. Importance of Brand Awareness and Brand Loyalty in assessing Purchase Intentions of Consumer. Int. J. Bus. Soc. Sci. 4, 165-170.

[7] Gelder, S. Van, 2004. Global brand strategy. J. Brand Manag. 12, 39-48.

[8] Gelder, S. Van, 2006. Unlocking Branding Potential Across Aountries, Cultures \& Markets, 1st ed. Kogan Page, London.

[9] Helms, M.M., Nixon, J., 2010. Exploring SWOT analysis - where are we now?: A review of academic research from the last decade. J. Strateg. Manag. 3, 215-251.

[10] Huang, R., Sarigöllü, E., 2012. How brand awareness relates to market outcome, brand equity, and the marketing mix. J. Bus. Res. 65, 92-99.

[11] Jackson, S.E., Schuler, R.S., Jiang, K., 2014. An Aspirational Framework for Strategic Human Resource Management. Acad. Manag. Ann. 8, 1-56.

[12] Karam, A.A., Saydam, S., 2015. An Analysis Study of Improving Brand Awareness and Its Impact on Consumer Behavior Via Media in North Cyprus ( A Case Study of Fast Food Restaurants ). Int. J. Bus. Soc. Sci. 6, 66-80.

[13] Kaye, D., 2014. Marketing to Millennials? Make It Personal and Customized. [WWW Document]. Entrepreneur. URL https://www.entrepreneur.com/article/234891

[14] Kotler, P., Keller, K.L., 2016. Marketing Management, 1st ed, Global Edition. Pearson Education Limited, Boston.

[15] Krake, F.B.G.J.M., 2005. Successful brand management in SMEs: a new theory and practical hints. J. Prod. Brand Manag. 14, 228-238.

[16] Kuratko, D.F., Hornsby, J.S., Covin, J.G., 2014. Diagnosing a firm's internal environment for corporate entrepreneurship. Bus. Horiz. 57, 37-47.

[17] Miles, M.B., Huberman, A.Mm., Saldaña, J., 2014. Qualitative data analysis: A methods sourcebook. SAGE Publications, Los Angeles.

[18] Morrison, A., Breen, J., Ali, S., 2003. Small Business Growth: Intention, Ability, and Opportunity. J. Small Bus. Manag. 41, 417-425.

[19] Rao Gundala, R., Khawaja, H., 2014. Brand Management in Small and Medium Enterprise: Evidence From Dubai, Uae. Glob. J. Bus. Res. 8, 27-38.

[20] Schultz, D.E., Patti, C.H., Kitchen, P.J., 2013. The evolution of integrated marketing communications: The customer-driven marketplace. In: The Evolution of Integrated Marketing Communications: The Customer-Driven Marketplace. pp. 1-134. 